\title{
Relações e conflitos entre crianças na Educação Infantil: o que elas pensam e falam sobre isso
}

\section{The relations and conflicts between children in the Kindergarten: their thinks and speechs about this}

\author{
Bianca Rodriguez Corsi ${ }^{1}$
}

\begin{abstract}
RESUMO
Atualmente corrobora-se a ideia da importância da infância e de dar voz às crianças, uma vez que estas são compreendidas enquanto sujeitos capazes de construir, transformar, produzir e reproduzir cultura. A partir deste novo paradigma e de uma problemática real da dinâmica de crianças da Educação Infantil, os conflitos interpessoais ocorridos entre elas, filmou-se e apresentou-se para as crianças, de 5 a 6 anos, cenas de suas rotinas objetivando que elas deem suas opiniões, hipóteses e sugestões acerca do que são conflitos e como se resolvem. Ouvir o que as crianças têm a dizer acerca dos conflitos que vivenciam valida a ideia da criança enquanto produtora de cultura e de conhecimento e, ainda, expande as possibilidades de pesquisa tendo como sustentação teórica e metodológica a Sociologia da Infância. Palavras-chave: infância; conflito; Wallon; sociologia da infância; cultura.
\end{abstract}

\begin{abstract}
Currently supports up with the idea of the importance of childhood and give voice to children, as these are understood as subjects able to build, transform, produce and reproduce culture. From this new paradigm and a real problem of the dynamics of children in Kindergarten, the interpersonal conflicts occurred between them, it is filmed and presented to the children,
\end{abstract}

${ }^{1}$ Mestre em Sociologia da Infância - Faculdade de Educação da Universidade de São Paulo, com a orientação da Profa. Dra. Maria Letícia B. P. Nascimento.

${ }^{2}$ Para saber mais, ver: SARMENTO, M. Lógica de acção nas escolas. Lisboa: Instituto de Inovação Educacional, 2000. 
5-6 years, scenes of their routines that they give their opinions, suggestions and hypotheses about what are and how conflicts are resolved. Listen to what children have to say about the conflicts they have lived validates the idea of the child as a producer of culture and knowledge, and also expands the possibilities of research having as theoretical and methodological Sociology of Childhood.

Keywords: childhood; conflict; Wallon; sociology of childhood; culture.

\section{Introdução}

A dinâmica do conflito nas turmas de Educação Infantil é uma problemática conhecida e discutida tanto nas instituições educacionais quanto por teóricos da pedagogia e da psicologia. O conflito possui, basicamente, duas perspectivas mais disseminadas. Num ponto de vista - difundido pelo senso comum -, o conflito é compreendido como algo próximo ao perigoso, algo que se confunde com afrontamento, rebeldia, crise, atos de egoísmo, brigas ou, ainda, como agressividade. Ainda que aparentemente negativa, essa perspectiva pode ser discutida a partir da produção de James, Jenks e Prout (1998), Pinto e Sarmento (1997, 2007), e Ferreira (2004). Em outra perspectiva, o conflito é concebido, resumidamente, como movimento constitutivo dos sujeitos e de suas identidades, por meio da preservação e afirmação do eu, sendo, portanto, realidade necessária para a formação da vida psíquica e social das crianças (WALLON, 1995, 1998).

Atualmente é possível encontrar pesquisas sobre conflito - sobretudo na área da psicologia - e suas interfaces com aspectos semelhantes e divergentes das duas perspectivas expostas no parágrafo anterior (GALVÃO, 2004). Nos estudos da psicologia, de maneira geral, os sujeitos dessa ação não têm sido consultados ou convidados a falar e a refletir acerca do mesmo, uma vez que as pesquisas existentes são feitas, sobretudo, a partir de observações em escolas pelo pesquisador. Sendo assim, estas pesquisas têm sido reduzidas ao ponto de vista do pesquisador e não daquele do grupo de crianças onde aconteceram as situações de conflito.

Deste modo, compreender a dinâmica de uma classe de Educação Infantil significa investigar as diversas tramas que nela se circunscrevem, observar os sujeitos que nela atuam, suas ações e reações. Representa o olhar da atividade infantil nos mais diversos ângulos - motriz, social, afetivo e intelectual - das crianças no seu meio, isto é, contextualizadas. Assim, para que se possa abarcar o objeto desta pesquisa, ou seja, as crianças, suas ideias e opiniões acerca dos conflitos que enfrentam, é necessário considerar estas enquanto: 
[...] produtoras ativas dos seus mundos de crianças, ou seja, como capazes de elaborar uma ordem social infantil que é uma visão intersubjetiva do mundo e um modo de estar no mundo, construídos social e culturalmente nas interações, relações sociais e dinâmicas de sociabilidade próprias no contexto do Jardim de Infância. (FERREIRA, 2004, p. 61).

Portanto, ouvir efetivamente o que elas podem dizer acerca dos conflitos subsidia a produção de novos conhecimentos para diversas pesquisas, procedimento que não só efetivará o discurso atual da importância da infância - e, consequentemente, das crianças enquanto produtoras de cultura -, como também assegurará, mesmo que num pequeno grupo, o direito deste falar sobre o que pensa, tendo suas ideias compreendidas enquanto algo a ser, realmente, respeitado.

\section{Trajetória metodológica e procedimentos}

Utilizou-se como referencial teórico para a compreensão e análise de conflitos a teoria de Henri Wallon, já que, dentre os teóricos da psicologia do desenvolvimento, foi ele quem destacou a presença do conflito como movimento constitutivo dos sujeitos.

Partindo da perspectiva walloniana, na qual as crianças têm papel ativo na construção de suas identidades, pode-se prosseguir provocando sua interlocução com teóricos da sociologia da infância, que trazem a proposta da participação ativa das crianças nas pesquisas, já que reconhecem nelas seus papéis enquanto "sujeitos em vez de objetos de pesquisa [o que] acarreta aceitar que elas podem 'falar' em seu próprio direito e relatar visões e experiências válidas" (ALDERSON, 2005, p. 423).

Nesse sentido, traçou-se como objetivo escutar as crianças, registrar suas ideias, falas e pensamentos, bem como filmar seus cotidianos para que se possa apreender, além das falas, suas expressões e relações estabelecidas com seus pares e com os adultos.

No que concerne à coleta de dados com as crianças, foi realizada em uma instituição privada de educação infantil na cidade de São Paulo, na zona sul, com uma classe de crianças com a faixa etária entre 5 e 6 anos de idade. Utilizouse o estudo de caso como metodologia de investigação - ou seja, "uma investigação empírica que investiga um fenômeno contemporâneo dentro do seu contexto real de vida, especificamente quando as fronteiras entre o fenômeno e o contexto são absolutamente evidentes" (YIN apud SARMENTO, 2003), por meio da abordagem interpretativa com orientação etnográfica, ou seja, uma abordagem em que a pesquisadora busque se tornar membro de determinado 
grupo, para que seja possível apreender a perspectiva das crianças (CORSARO, 2005 , p. 444), a partir da sua participação junto às suas formulações ${ }^{2}$, tendo sempre como enfoque a recolha de suas falas.

Vale ressalvar que, antes de se iniciar a pesquisa, foi esclarecida junto às crianças a proposta da investigação: pesquisar o que as crianças pensam acerca de conflitos. Para tanto, foram expostos os diferentes instrumentos de registro (papel, gravador e filmadora) que seriam utilizados para a verificação e se todos os aceitavam. Como a resposta foi afirmativa, tiveram início os registros das falas e cenas propostas, bem como a exploração desta metodologia que, aos poucos, foi se delineando junto aos conflitos ocorridos no grupo.

\section{Categorização e preparação dos materiais coletados}

Para que o material ficasse com a qualidade esperada, foi necessário assistir incalculáveis vezes aos vídeos coletados. Durante estas sessões, buscou-se atentar às expressões corporais, sobretudo as faciais, das crianças, na tentativa de buscar algum tipo de insatisfação quando esta não estava evidente por meio de reclamações verbais.

Evidentemente, a diversidade das possibilidades de conflitos não pôde ser abarcada nesta pesquisa, até porque este não é seu objetivo. Este recorte feito na escolha de conflitos a serem apresentados foi definido a partir da ideia de que as crianças são as protagonistas deste trabalho. Sendo assim, o olhar da pesquisadora sobre o que esta considera enquanto conflito não se faz importante, mas sim o que a criança concebeu e defendeu enquanto problema, sendo capaz de exprimir e/ou verbalizar durante o momento em que o conflito ocorreu. Sendo assim, as cenas selecionadas vão ao encontro desta ideia: momentos que retratam as discussões, brigas, questionamentos das crianças para com outros colegas.

Ao assistir diversas vezes aos vídeos, percebeu-se que seria difícil adotar uma postura divergente da exposta acima, já que as cenas apreendidas neles são, em grande parte, de momentos que justamente evidenciem este tipo de situação. Esta análise demonstrou e, até certo ponto, surpreendeu pela excessiva quantidade de situações em que os meninos - na totalidade dos casos - utilizaram a força física para tentar resolver alguma questão que os incomodava. A ausência total ou parcial do diálogo em situações de desacordo também foi uma constante nas situações gravadas.

Por conseguinte, as cenas escolhidas para a amostragem retratam justamente estas situações, momentos em que as crianças teriam a possibilidade de resolver alguma insatisfação utilizando os mais diversos artifícios, porém valeram-se da força física e/ou do aumento da voz para obter o que pretendiam. 
Cenas que, muitas vezes, chocaram até mesmo a pesquisadora, dado o caráter hostil de muitas delas.

Enfim, o vídeo final foi composto por dezessete cenas, totalizando 13 minutos e 45 segundos. Cada cena foi intercalada com frases que, de alguma forma, caracterizavam o que ocorreu na dita cena.

\section{O que as crianças pensam sobre o conflito?}

Durante a apresentação do vídeo ao grupo, foram gravadas as falas das crianças acerca do que viam por meio da filmadora e de um gravador: cada criança que quisesse expor algo acerca do que assistia, requisitava o gravador para a última criança que o segurava.

A partir do mapeamento e da categorização das falas transcritas das crianças enquanto assistiam ao vídeo, foi possível elaborar um quadro para representar o que elas disseram, bem como perceber algumas constâncias e alternâncias de postura, linguagem e pensamento.

Esta percepção desencadeou uma nova hipótese e, portanto, um novo direcionamento para esta pesquisa. Trata-se da forma como diversas crianças se posicionaram no momento de verbalizarem algo acerca das cenas de conflito: muitas buscaram, por meio da linguagem, atender à expectativa dos adultos presentes durante a exposição do vídeo, reproduzindo fielmente as falas que as educadoras têm no momento em que fazem a mediação de diversos conflitos ocorridos no cotidiano, como, por exemplo, contar para o colega o que não gostou, a sugestão de tentar conversar e a proposta de tanto pedir desculpas para o colega quanto a de desculpá-lo.

Esta hipótese surgiu a partir da inquietação que algumas frases recorrentes deixaram. Após diversas leituras da transcrição das falas e, em seguida, da marcação em cores diferentes justamente das falas recorrentes, ficou evidente a repetição de diversas delas no início da discussão que, gradativamente, se tornaram menos evidentes, permanecendo apenas em um pequeno grupo de meninas. Talvez esta diminuição de reproduções tenha ocorrido na medida em que as crianças se envolveram mais com as cenas, desprendendo-se das falas que seriam para o adulto rumo às falas que lhes são próprias, espontâneas e caracterizadas justamente por esta espontaneidade.

A suposição exposta no parágrafo anterior pode ser facilmente percebida por meio de dois exemplos distintos. Um deles é a percepção da diferença de suas falas durante os instantes em que, por algum motivo, estavam empolgadas/ excitadas: as falas como "não gostei", "deveriam conversar", "pedir desculpa", "nunca mais fazer isso" tornam-se ausentes, já que a espontaneidade tomou 
conta da linguagem do interlocutor, não se preocupando/restringindo, portanto, em atender a uma expectativa do adulto, mas sim de expressar o que estão pensando naquele presente momento acerca da cena que viram. Outro exemplo, um pouco mais contundente, trata das respostas que diversas crianças forneceram diante de questionamentos da pesquisadora sobre qual sugestão eles poderiam dar para a criança da cena ou o que acharam dela: prontamente muitas respondiam "não pode bater" - ainda que na cena não tenham surgido agressões físicas. Um exemplo ilustrativo para isso é a forma como uma criança respondeu rapidamente a uma pergunta acerca da maneira como ela e outras crianças lidaram para resolver um determinado conflito (cena 5):

Bianca: Vocês deviam estar com algum problema, como vocês resolveram?

\section{C.: Conversando}

Bianca: Vocês resolveram conversando?

C.: Aham (fez que sim com a cabeça)..., não, batendo.

E, efetivamente, foi utilizando a força física que as crianças envolvidas na cena tentaram, de alguma forma, lidar com o que pretendiam resolver.

Porém, mais relevante do que expor hipóteses neste momento é trazer o que finalmente as crianças disseram acerca dos conflitos que viram. Sendo assim, abaixo segue a análise feita das falas gravadas durante a apresentação das cenas, sem pormenorizar aquelas que, por vários motivos, atendem à ideia exposta acerca da hipótese elaborada, uma vez que esta traz a análise do ponto de vista do adulto e do que este considera ser próprio da criança, ainda que isto pudesse promover uma interessante discussão acerca das teorias de produção e reprodução de culturas no ambiente educacional.

Assim, a partir do material coletado foram elaborados, a priori, dois quadros: um acerca do que as crianças definiram enquanto conflito e outro das resoluções para ele. Porém, com ambos em mãos, percebeu-se a necessidade de fazer uma nova divisão no primeiro, já que ficaram evidentes, nas falas das crianças, duas ideias complementares - porém divergentes - de conflito: o que é e o que causa. Diante desta questão, a pesquisadora buscou apontar, nas falas, o caráter de cada uma delas para efetivar a ideia acima: distinguir o que é do que causa conflito. Porém, dado o caráter subjetivo de muitas delas, a pesquisadora optou por manter a ideia original sem, no entanto, deixar de pontuar, neste momento, tais singularidades que surgiram no transcorrer das leituras dos materiais coletados. Sendo assim, a análise discorrerá sobre dois ângulos: o que as crianças definem como conflito, acerca da perspectiva de como e por que ocorrem, e, por fim, como se resolve um conflito, apontando ainda, as propostas suscitadas pelas crianças. 
CORSI, B. R. Relações e conflitos entre crianças na educação infantil...

O que elas definem como conflito. Como e por que ocorrem?

Antes de introduzir a análise feita acerca das falas das crianças, faz-se interessante expor o quadro elaborado a partir das mesmas:

\begin{tabular}{|l|c|}
\hline \multicolumn{2}{|c|}{ Categorias do que é e/ou o que causou conflito } \\
\hline Uma criança (ou grupo) machucar/ofender a outra & 29 \\
\hline Crianças se machucando/ofendendo mutuamente & 11 \\
\hline Não conseguir/esquecer de conversar & 3 \\
\hline Engano & 2 \\
\hline Ver algum amigo chorando & 2 \\
\hline Brincar com algo que não é de brincar/não é brincadeira & 2 \\
\hline Deixar alguém triste & 1 \\
\hline Não respeitar & 1 \\
\hline Não poder fazer isso com as pessoas & 1 \\
\hline Alguém ter se machucado sozinho & 1 \\
\hline Crianças pularem no colchão & 1 \\
\hline
\end{tabular}

Por meio deste quadro, é possível perceber diferentes significados que a ideia de conflito assume a partir das falas das crianças. Porém, ainda que distintas, é possível vislumbrar alguns agrupamentos que tornam essas diferentes concepções em algo, no mínimo, inter-relacionado. Tratam-se das seguintes categorizações (ou dimensões) a partir da feita inicialmente - como mostra o quadro acima - acerca da compreensão que as crianças têm de conflito: dimensão física, dimensão emocional, dimensão coletiva e, por fim, ocasional.

\section{Dimensão física}

A dimensão física é, de forma considerável, a que mais surge no discurso das crianças, Esta dimensão abarca a ideia de conflito enquanto algo relacionado à agressão física, ou seja, parte abundante dos conflitos ocorre ou tem sua origem no momento em que uma criança machuca com intenção a outra e, ainda, se esta revida ou não. Ainda nesta dimensão, foi possível perceber a distinção que as crianças fazem de conflito em duas vertentes: quando uma criança (ou grupo) bate em outra e quando crianças se batem mutuamente. A partir desta concepção e da incidência em que surge nas falas, fica clara a ideia de que, do ponto de vista da criança, bater em alguém, sem que a que foi machucada revide, é um conflito menos tolerável do que quando duas crianças se batem mutuamente, e, portanto, o maior problema é quando um criança ou grupo fere outra, e não se duas ou mais estão se agredindo. 
Assim, talvez possa se concluir que a questão não é o bater por si próprio, mas sim a responsabilidade - ou parcela de culpa - que a criança assume durante o desenrolar do conflito e a agressão que pratica em relação ao outro. Portanto, a partir das falas das crianças, a agressão física não é tolerável, porém ela é ainda menos aceitável se não ocorreu de forma recíproca.

\section{Dimensão emocional}

Outra dimensão que pôde ser percebida é a emocional, ou seja, quando o conflito surge de - ou tem enquanto consequência - algum tipo de agressão aos sentimentos de uma criança. No quadro, esta dimensão assume as seguintes categorias: "Ver algum amigo chorando", "deixar alguém triste" e "não poder fazer isso com as pessoas".

Assim, é possível notar a relação que as crianças estabelecem não só do conflito como algo que machuca fisicamente outra pessoa, mas também como algo que a deixa triste, desequilibrando-a emocionalmente.

\section{Dimensão coletiva}

Já a dimensão coletiva representa os conflitos que surgiram a partir do não cumprimento aos combinados elaborados pelo grupo ("Não conseguir/esquecer de conversar", "Brincar com algo que não é de brincar/não é brincadeira", "Crianças pularem no colchão"), como também pelos combinados estipulados socialmente, como, por exemplo, o dever se respeitar as pessoas ("Não respeitar").

Sendo assim, o conflito também representa parte da consciência coletiva que as crianças têm do grupo, ou seja, a percepção acerca da necessidade de se buscar cumprir os combinados existentes para que não ocorram problemas/ desentendimentos dentro do próprio grupo.

\section{Dimensão ocasional}

Por fim, tem-se a dimensão ocasional que, como próprio nome já sugere, envolve conflitos que se sucederam a partir do acaso. Ou seja, desentendimentos que ocorreram devido a algum engano ou sem propósito, como, por exemplo, quando uma criança senta em algum lugar que já tinha sido delimitado por outra sem que ela tivesse conhecimento disso, deixando a segunda brava por ter pegado seu lugar. Outro exemplo muito comum se refere à situação de quando uma criança chama ou escreve o nome de outra incorretamente, deixando seu colega chateado ou até mesmo bravo por tal equívoco.

Vale ressalvar que esses enganos muitas vezes levam a tortuosos conflitos, uma vez que a percepção de que foi não proposital é difícil de ser assimilada 
pela criança, já que a distinção entre uma agressão (física ou verbal) e um engano geralmente só é percebida por meio da intervenção de outros colegas e adultos que compreenderam o ocorrido. No quadro elaborado, verificam-se os itens "Engano" e "Alguém ter se machucado sozinho" que vão ao encontro desta ideia.

Portanto, além das crianças perceberem o conflito enquanto causa e consequência de dimensões físicas, emocionais e coletivas, ele também é notado como algo que não era para ser proposital, mas acaba, em alguns momentos, tornando-se como tal quando integrantes do grupo não o percebem desta maneira.

\section{O que dizem sobre suas estratégias e possibilidades de resolução}

Agora, após ter sido possível delinear o que as crianças deste grupo ponderam enquanto conflito e as variáveis que consideram para tais delimitações, iniciar-se-á uma análise das sugestões que o grupo em foco trouxe para a resolução deles.

Como proposto no item anterior, seguir-se-á neste momento primeiramente o quadro elaborado das categorias encontradas acerca das resoluções de conflito, para, em seguida, expor a análise feita.

\begin{tabular}{|l|c|}
\hline \multicolumn{2}{|c|}{ Categorias de resoluções de conflito } \\
\hline Conversar & 14 \\
\hline Não bater & 5 \\
\hline Pedir desculpas & 4 \\
\hline Não fazer mais isso & 2 \\
\hline Levar bronca & 1 \\
\hline Explicar para o amigo o que aconteceu & 1 \\
\hline Falar para as professoras & 1 \\
\hline Acalmar & 1 \\
\hline Melhorar & 1 \\
\hline Desculpar & 1 \\
\hline Nunca mais brigar & 1 \\
\hline
\end{tabular}

Sendo reflexo ou não da produção e reprodução da cultura adulta, parte significativa das sugestões estava na necessidade de se conversar com a outra criança (ou grupo) acerca do que estava acontecendo para se tentar solucionar o conflito. Ainda que não explicitado no quadro, parte importante destas sugestões surgiu justamente em oposição ao bater, ou seja, para que, durante 
um conflito, as crianças não utilizem a força física para lidarem com o problema, é necessário que se tente conversar.

Provavelmente em decorrência da forte concepção de conflito enquanto causa ou consequência justamente das agressões físicas - ainda que não a única, como exposto anteriormente -, a conversa enquanto alternativa para ela é presente, bem como o segundo item mais citado pelas crianças: "Não bater". Porém, como evidentemente estes dois pontos de vista mencionados pelas crianças não estão isolados, diversas outras sugestões foram mencionadas.

A partir do grupo de sugestões, assim como no momento da definição de conflitos foi possível delimitar algumas semelhanças e divergências nas propostas. Sumariamente, elas foram agrupadas em propostas para evitar um conflito, para saber lidar com o conflito no momento em que ele está ocorrendo e, por fim, sugestões do que fazer após ele já ter se desenvolvido.

No grupo de propostas para se evitar um conflito, tem-se: "nunca mais fazer isso", "melhorar" e "nunca mais brigar". Assim, o grupo de crianças pesquisado tem, enquanto concepção, que conflitos podem ser evitados utilizando certas estratégias, como, por exemplo, nunca mais repetir determinada atitude ou, outra ainda mais otimista, melhorar para nunca mais fazer isso.

Em relação ao grupo de sugestões que focaram o que fazer após o conflito e sua resolução, encontram-se as seguintes possibilidades: "desculpar", "ser desculpado" e, ainda, ser punido: "levar bronca". É perceptível a noção que algumas crianças têm de buscar ser desculpado após o ocorrido - tanto a criança que o iniciou, quanto a que nada possa ter feito. E, ainda, a ideia de punição: a criança deve levar uma bronca para aprender a nunca mais fazer o que fez.

Já as sugestões para conseguirem lidar com o conflito no momento em que ele ainda está ocorrendo são mais generosas no sentido de possibilidades de estratégias. As crianças fizeram as seguintes sugestões: "Conversar", "Não bater", "Explicar para o amigo o que aconteceu", "Falar para as professoras" e "Acalmar".

A partir deste mapeamento das estratégias para resolução de conflitos, ficou patente a ideia das crianças de que é preciso tentar lidar com ele no momento em que ocorre, buscando soluções isoladamente ou por meio da ajuda/intervenção de outras pessoas. Porém, fica evidente também que as crianças não deixam de pontuar tanto um olhar que antecede quanto um que sucede o conflito, ou seja, meios e maneiras para se pensar o conflito tanto no sentido de evitar que ele volte a ocorrer como no sentido de saber lidar com ele durante e depois. 


\section{O olhar do adulto e as contribuições da criança para a pesquisa}

A partir da análise dos materiais coletados e da percepção de suas possibilidades, decidiu-se expor duas vertentes importantes para a discussão teórica acerca da temática desta pesquisa. Trata-se de pontos que impreterivelmente buscarão constituir a relevância que esta pesquisa teve ao que concerne à investigação das ideias das crianças acerca do que são os conflitos.

Para isso, decidiu-se expor duas possibilidades de análise: uma referente ao conteúdo das falas em relação aos conhecimentos difundidos atualmente acerca de conflito na perspectiva walloniana, e, outra, concernente às contribuições da escuta da criança e seu significado para a discussão atual, circunscrita à área da Sociologia da Infância.

Essa divisão das discussões não tem por objetivo sugerir ou implicar na suposição de que são incompatíveis as ideias que as compõem, tornando-as estanques ou inconciliáveis; pelo contrário, esta divisão meramente ilustrativa tem por finalidade enriquecer pela sua complementaridade e, precisamente, pelas possibilidades de investigação e expansão da temática abordada nesta presente pesquisa em outras áreas do conhecimento, sejam sociológicas, sejam psicológicas.

Assim, seguem abaixo a discussão acerca da ideia de conflito constitutivo e, ainda, as contribuições que as crianças possibilitaram ao discursarem sobre ele.

\section{Conflito constitutivo? Eis uma questão}

A partir da psicogenética de Wallon, como já mencionado anteriormente, o conflito está intrinsecamente relacionado com a constituição da identidade dos sujeitos - e, por isso, tem o nome de conflito constitutivo. Esse processo de constituição iniciar-se-á mais acirradamente por volta dos 3 anos de idade, momento em que as crianças adentrarão as crises de oposição, nas quais buscarão construir o seu eu a partir necessariamente do outro - aquele que não sou eu e, portanto, o que Wallon nomeou como não-eu. A negação de tudo o que não representa o $e u$ favorecerá a entrada da criança numa investigação de si mesma e, assim, numa descoberta e compreensão de quem ela é para, então, constituir - ainda que num processo inacabado - sua identidade a partir da preservação e afirmação de si mesma, do eu.

Contemplando esta perspectiva, o conflito é compreendido, portanto, enquanto movimento necessário na formação dos sujeitos e não como algo negativo que degrada a constituição da identidade destes. É justamente devido a este ponto de vista que Wallon se tornou autor de referência nesta pesquisa, 
pois, diferentemente de outros que o antecederam, compreende e analisa a criança de forma contextualizada, relevando as relações que esta estabelece com o outro, consigo mesma e com o meio no sentido de complementação de si própria com estes elementos e não enquanto interferência negativa na sua forma de ser e estar no mundo.

Assim, a teoria walloniana, ao apontar a necessidade de estar atento para as emoções e para os processos de construção da personalidade das crianças, inserindo o contexto e as relações estabelecidas nele, traz para o campo da pesquisa a inserção e a valorização dos processos que elas elaboram desde sua existência. Corroborando, portanto, com os objetivos que hoje são pesquisados na chamada Sociologia da Infância, uma vez que esta, ao privilegiar o olhar também nas construções que as crianças participam de forma ativa, produzindo e reproduzindo cultura em seus contextos, credita aos pequenos a autoria da formação e da constituição de suas identidades a partir das relações que estabelecem consigo, com o outro e com o meio, compreendendo neste tripé a realidade necessária para a consolidação tanto da identidade de cada criança quanto da valorização das culturas infantis.

Porém, ainda assim, prevalece uma pergunta: será que os conflitos que as crianças vivenciaram e puderam assistir no vídeo têm caráter constitutivo, ainda que quase a totalidade das cenas tenha sido marcada pela agressão física entre as crianças? Ou será que as cenas remetem a crises de violência entre as crianças e, assim, nada têm de constitutivos, mas sim de destrutivos?

Izabel Galvão trouxe em seu livro Cenas do cotidiano escolar: conflito sim, violência não, um mapeamento de perspectivas de diversos autores acerca do que são conflitos. Dentre elas, há algumas que sugerem tal questionamento e uma delas é a de Wieviorka, que opõe conflitos à violência, por exemplo, afirmando que aqueles:

[...] baseiam-se em lógicas contrárias. No conflito, as pessoas ou grupos que se opõem buscam reforçar suas posições relativas na relação. Nele, aponta-se para a possibilidade de um compromisso entre os oponentes. A violência, por sua vez, aponta para a ruptura da relação, para a destruição do outro. Por essa definição, a violência floresce quando o conflito falha, quando ele é inoperante ou impotente para assegurar uma unidade mínima entre as partes em oposição. (GALVÃO, 2004, p. 17).

Porém, Wallon aponta para outra perspectiva ao justamente compreender nas relações que as crianças estabelecem umas com as outras um afrontamento no sentido de preservarem e/ou afirmarem suas identidades, imersas em sentimentos e emoções. 
Prosseguindo e retomando este ponto de vista, a criança passa a constituir sua personalidade a partir de relações e diferenciações que estabelecem com seus pares, justamente numa fase marcada por crises de caráter emocional. Essas crises, como definiu Galvão, são os momentos em que "[...] o sujeito mergulha-se completamente nos efeitos da emoção e perde o controle sobre suas próprias ações" (GALVÃO, 1995, p. 64) e que, portanto, pode utilizar-se de elementos físicos para dar vazão as suas necessidades de impor-se no sentido de afirmar ou diferenciar o eu daquilo que não o é, sem se dar conta, ter dimensão ou controle daquilo que efetivamente está fazendo, da sua ação.

Sendo assim, as agressões físicas entre as crianças não deixam de ter caráter constitutivo, uma vez que estas representam um prolongamento das emoções com as quais estão lidando diante do conflito e que ainda não têm total controle acerca delas. Esta capacidade de controlar suas próprias ações, chamada por Wallon de disciplinas mentais, "[...] está ligada ao amadurecimento dos centros de inibição e discriminação situados no córtex cerebral, que se dá por volta dos seis, sete anos" (GALVÃO, 1995, p. 75).

Assim, como bem prossegue a autora, "antes dessa idade, a possibilidade de a criança controlar voluntariamente suas ações é pequena" (GALVÃO, 1995, p. 75-76). Idade justamente que os agentes desta pesquisa estão em vias de alcançar ou há pouco alcançaram, ainda que esta idade a que Wallon se refere seja apenas indicativa, uma vez que varia de acordo com o contexto em que as crianças se inserem.

A partir desta explanação teórica, talvez seja possível retomar a pergunta proposta no início deste item: será que os conflitos tratados nesta pesquisa possuem caráter constitutivo ou não? A pesquisadora concluiu que os conflitos citados e apresentados para as crianças possuem caráter constitutivo sim, na medida em que retratam as crises da composição do eu, seja na negação do não-eu, seja na afirmação desse eu. E, por fim, para corroborar com esta hipótese, têm-se as contribuições das opiniões das crianças acerca dos conflitos, nas quais ficou evidente seu surgimento a partir de relações que as crianças estabeleceram com outras e que, por algum motivo, tiveram caráter ofensivo, seja com alguma criança ou grupo, seja com os combinados e regras estabelecidos no mesmo; que, de alguma forma ou por algum motivo, não vão ao encontro do que elas julgam ser justo ou adequado.

A escuta da voz das crianças: suas contribuições a partir do olhar sociológico

Mas, enfim, o que significam estas falas? Qual a importância de ouvilas? E, ainda, qual a sua relação com a sociologia? 
Primeiramente, faz-se importante evidenciar, ainda que de forma sucinta, o atual papel que a sociologia está assumindo a partir da perspectiva de Sarmento e Pinto, pesquisadores portugueses proeminentes na discussão acerca da importância da infância. Eles afirmam que, a sociologia, está buscando

[...] constituir a infância como objeto sociológico, resgatando-a das perspectivas biologistas, que a reduzem a um e para eles. Porém, mais do que isso, a sociologia da infância propõe-se a interrogar a sociedade estado intermédio de maturação e desenvolvimento humano, e psicologizantes, que tendem a interpretar as crianças como indivíduos que se desenvolvem independentemente da construção social das suas condições de existência e das representações e imagens historicamente construídas sobre a partir de um ponto de vista que toma as crianças como objeto de investigação sociológica por direito próprio, fazendo acrescer o conhecimento, não apenas sobre infância, mas sobre o conjunto da sociedade globalmente considerada. (SARMENTO, 2005, p. 363).

Defendem ainda que, para realmente concebermos as crianças como atores sociais de plenos direitos, devemos não somente perceber como também corroborar com sua capacidade de construção de cultura, a partir da possibilidade deles atribuírem sentido às suas ações, de produzirem simbolicamente e, também, de constituírem suas representações e crenças em sistemas organizados. Ambos os pesquisadores asseguram, ainda, que as culturas infantis não surgem no "universo simbólico exclusivo da infância", pois este não é "fechado - pelo contrário, é, mais do que qualquer outro, extremamente permeável - nem lhes é alheia a reflexividade social global". (PINTO; SARMENTO, 1997, p. 6).

Sendo assim, é possível compreender a constante mutação da infância, visto que ela é o reflexo do que as crianças produzem em seus contextos atuais, de uma vida que é dinâmica, que muda constantemente e, portanto, faz parte de uma permanente construção cultural, fruto das inconstantes ideias da sociedade na qual as crianças estão inseridas. Assim,

A interpretação das culturas infantis, em síntese, não pode ser realizada no vazio social, e necessita de se sustentar na análise das condições sociais em que as crianças vivem, interagem e dão sentido ao que fazem. (PINTO; SARMENTO, 1997, p. 6).

Portanto, conhecer o que as crianças têm a dizer sobre o conflito, algo que certamente está em seu cotidiano e do qual de alguma maneira não podem escapar, já que fazem parte de um meio social no qual há diversos outros agentes que também conflitam, é algo necessário e enriquecedor acerca do que ainda não se sabe sobre elas, das lógicas e estratégias que são características das 
crianças nestas situações. Tão relevante quanto este aspecto é a possibilidade de elaborar um trabalho no qual as crianças sejam protagonistas da pesquisa, enquanto seres de direitos que devem ser ouvidos, para que, desta maneira, o discurso atual acerca da importância das crianças e da infância transcenda da fala para a ação.

Dar voz e ouvido às crianças acerca da temática do conflito significa, por fim, valorizar sua cultura, suas resoluções e explicações acerca de seu cotidiano, ou seja, considerar as crianças

[...] como actores sociais de pleno direito, e não como menores ou como componentes acessórios ou meios da sociedade dos adultos, implica o reconhecimento da capacidade de produção simbólica por parte das crianças e a constituições das suas representações e crenças em sistemas organizados, isto é, em culturas. (PINTO, 1997, p. 20).

\section{Considerações finais}

Esta pesquisa adentrou a rotina de crianças da Educação Infantil com um objetivo central: ouvir o que as crianças dizem sobre os conflitos. Esta iniciativa só pôde ser concretizada ao se partir do pressuposto de que elas são atores sociais que produzem e reproduzem cultura a partir do mundo adulto e, portanto, são sujeitos capazes de elaborar suas próprias hipóteses acerca da rotina que vivenciam e, assim, dos conflitos que lidam, sugerindo alternativas, propondo ideias para sua resolução.

Mas, afinal, o que as crianças disseram sobre conflitos? Ou, ainda, qual a relevância de escutar tais falas? Por meio de suas falas, as crianças acabaram por corroborar duas interessantes ideias que estão intrinsecamente relacionadas. Uma primeira é a do conflito enquanto elemento para constituir suas identidades por meio da afirmação e preservação do eu, desconstruindo, assim, hipóteses redutoras deste movimento que ocorre de forma intensa na rotina da Educação Infantil (porém não somente nela), como, por exemplo, de que são as crianças mais agitadas ou, ainda, as endiabradas ou violentas que incitam os conflitos. Em suas argumentações, foi possível apreender diversas categorias do que são e como se pode fazer para resolvê-los, o que mostrou o repertório de sugestões que não se constitui apenas enquanto reprodução do mundo adulto, mas sim um diálogo que as crianças são capazes de estabelecer com o mesmo, transpondo e transformando as informações que julgam pertinentes dele. Uma segunda ideia - porém não menos importante - trata justamente da importância de 
concebê-los como seres produtores de cultura e, portanto, da eminência de analisar cada vez mais suas falas, uma vez que elas ampliam e enriquecem o repertório do pesquisador que busca investigar com seriedade a infância a partir de um olhar sociológico.

Ouvir o que as crianças têm a dizer do que "elas veem, como sentem, o que temem e o que desejam na sua experiência educativa" (CAMPOS; CRUZ, 2006, p. 12), e não somente observá-las e registrar o que o olhar adulto pôde captar de suas rotinas, não somente traz como também valida, de forma efetiva, o discurso atual da importância da infância tão trabalhado nesta pesquisa, inserindo as crianças de forma ativa na mesma, uma vez que se faz necessário concebê-las como sujeitos produtores de cultura num contexto que é dinâmico e, portanto, que está permanentemente em processo de construção.

E, ainda, juntamente com este propósito, conceber o conflito como constitutivo e, portanto, como algo necessário na formação dos sujeitos, corrobora com a desconstrução de diversos estereótipos que ainda acompanham o olhar do adulto acerca das crianças, as imagens sociais que as reduzem como, por exemplo, de criança má, inocente ou naturalmente desenvolvida.

Assim, constituir a Sociologia da Infância enquanto parte da ciência da qual se originou - a Sociologia - e que esteja atenta à complexidade das condições de existência das crianças se faz imprescindível. Uma ciência que credite na voz das crianças a possibilidade de desconstruir imagens já estabelecidas sem se esquecer de estar atenta para a não formação de novas imagens que novamente reduzam as crianças em seres $a$-críticos, $a$-políticos, $a$-sociais. (SARMENTO, 2007).

Por fim, como bem afirmou Sarmento, faz-se necessária uma ciência que, em suma,

[...] faça da voz das crianças não o outro da voz dos adultos (não já silenciada, mas reduzida e filtrada pelo processo analítico empregue), mas a expressão de uma alteridade que se conjuga na sua diferença face aos adultos. (SARMENTO, 2007, p. 45).

\section{REFERÊNCIAS}

ALDERSON, P. As crianças como pesquisadoras: os efeitos dos direitos de participação sobre a metodologia de pesquisa. In: Educação e Sociedade: Revista de Ciência e Educação, São Paulo: Cortez; Campinas: Cedes, v. 26, n. 91, p. 419-442, 2005. 
ARIÈS, P. O sentimento da infância. In: . História social da criança e da família. Rio de Janeiro: Jorge Zahar Editores, 1981.

ARROYO, M. O significado da infância. In: SIMPÓSIO NACIONAL DE EDUCAÇÃO INFANTIL, 1994. Anais... Brasília: MEC, 1994.

CAMPOS, M. M.; CRUZ, S. H. V. Consulta sobre qualidade na Educação Infantil: o que pensam e querem os sujeitos desse direito. São Paulo: Cortez, 2006.

CORSARO, W. Pesquisa etnográfica realizada com as crianças de jardins de infância nos Estados Unidos e na Itália. Braga: U. Minho/Instituto de Estudos da Criança, 2003.

. Entrada no campo, aceitação e natureza da participação nos estudos etnográficos com crianças pequenas. Educação e Sociedade: Revista de Ciência e Educação, v. 26, n. 91, p. 443-464, 2005.

FARIA, A. L. G.; DEMARTINI, Z. B. F.; PRADO, P. D. (Orgs). Por uma cultura da Infância: metodologia de pesquisa com crianças. Campinas: Autores Associados, 2002.

FERREIRA, M. Do avesso do brincar ou... As relações entre pares, as rotinas da cultura infantil e a construção da(s) ordem(ens) social(ais) instituinte(s) das crianças nos jardins de infância. In: SARMENTO, M.; CERISARA, A. B. Crianças e miúdos: perspectivas sociopedagógicas da infância e educação. Lisboa: Edições ASA, 2004.

GALVÃO, I. Henri Wallon: uma concepção dialética do desenvolvimento infantil. Petrópolis: Vozes, 1995.

. Emoções e conflitos: análise da dinâmica das interações numa classe de educação infantil. Águas de Lindóia, SP: Fundação Orsa, 1998.

A análise dos conflitos como eixo para a reflexão sobre a prática pedagógica. Pro-posições, v. 12, n. 2-3, p. 122-140, jul.-nov. 2001.

. Expressividade e emoções segundo a perspectiva de Wallon, In: ARANTES, Valéria Amorim (Org.). Afetividade na escola: alternativas teóricas e práticas. São Paulo: Summus, 2003. 
. Cenas do cotidiano escolar: conflito sim, violência não. Petrópolis:

Vozes, 2004.

JAMES, A.; JENKS, C.; PROUT, A. Theorizing Childhood. Cambridge: Polity Press, 1998.

PINTO, M.; SARMENTO, M. J. As crianças e a infância: definindo conceitos, delimitando campo. In: SARMENTO, M. J.; PINTO, M. As crianças: contextos e identidades. Braga: Centro de Estudos da Criança, Universidade do Minho, 1997.

SARMENTO, M. J. O estudo de caso etnográfico em educação. In: ZAGO, N.; CARVALHO, M. P.; VILELA, R. A. T. (Orgs.). Itinerários de pesquisa: pesquisas qualitativas em Sociologia da Educação. Rio de Janeiro: DP\&A, 2003. p. 137-149.

. Gerações e alteridade: interrogações a partir da sociologia da infância. Educ. Soc., Campinas, v. 26, n. 91, p. 361-378. 2005.

. Visibilidade social e estudo da infância. In: VASCONCELLOS, V. M. R.; SARMENTO, M. J. (Org.). Infância (in)visível. Araraquara: Junqueira \& Marin, 2007.

WALLON, H. As origens do caráter da criança. São Paulo: Nova Alexandria: 1995. . A evolução psicológica da criança. Lisboa: Edições 70, 1998.

Texto recebido em 30 de abril de 2009.

Texto aprovado em 10 de outubro de 2009. 